\title{
Unmet Demand for Walkable Transit-Oriented Neighborhoods in a Midsized Canadian Community: Market and Planning Implications
}

\author{
Lawrence D. Frank, Jerome Mayaud, Andy Hong, Pat Fisher, Suzanne Kershaw \\ Lawrence D. Frank ${ }^{1}$, Jerome Mayaud ${ }^{1}$, Andy Hong ${ }^{2}$, Pat Fisher ${ }^{3}$, Suzanne Kershaw ${ }^{4}$ \\ ${ }^{1}$ The University of British Columbia, Vancouver, BC, Canada \\ ${ }^{2}$ University of Oxford, The George Institute for Global Health, Oxford, UK \\ ${ }^{3}$ Region of Waterloo Public Health, Waterloo, ON, Canada \\ ${ }^{4}$ Urban Design 4 Health, Vancouver, BC, Canada \\ Corresponding Author: Lawrence D. Frank, School of Population and Public Health, The \\ University of British Columbia, 1633 West Mall, Vancouver, BC, Canada V6J 1B6. Email: \\ lawrence.frank@ubc.ca
}

\begin{abstract}
Understanding neighborhood preferences remains a key focus for planners. While many studies document the effects of either neighborhood design or neighborhood preference on health and travel behavior, few have explored their combined effect in smaller regions. Using a sample of 2,597 adults in the Region of Waterloo, Ontario, we found an unmet demand for walkable neighborhoods. Results suggest that walkable neighborhoods are independently associated with less vehicle travel after adjusting for sociodemographic and residential preferences. Our study highlights the importance of combining the effects of walkable neighborhoods and preferences for them when addressing health and sustainability goals in suburban communities.
\end{abstract}

\section{Highlights}

- We model demand for walkable development in a mid-sized city region in Canada

- We find moderate unmet demand for walkable development

- Even when controlling for neighborhood preference, neighborhood design is associated with utilitarian and recreational walking and vehicle kilometers travelled

- Obesity may be shaping people's preference for low walkable neighborhoods

- Unmet demand for walkable development may adversely impact active transportation

\section{Keywords}

Neighborhood preference, walkability, active transportation, mid-sized cities 


\section{Introduction}

The extent to which neighborhood preference and design affect health and travel behavior remains a key question for urban planners. This question could be especially important in the context of smaller communities, where choices for residential environments are reduced compared with larger cities. Residential location choice involves various trade-offs including cost, property characteristics, and transportation accessibility, and is known to vary by socioeconomic profile. However, uncertainty remains about the role of "self-selection" in attracting certain people to walkable or unwalkable neighborhoods, and the resulting impacts on physical activity, travel choices, and health outcomes. Therefore, it is possible that as walkable environments become more popular generally, planning interventions that favor such neighborhoods may result in increased walking only among certain population groups. Better understanding of these connections can help planners to effectively impact active transportation in the region.

\section{Literature Review}

Positive associations between the walkability of the neighborhood in which people reside and their travel behavior and physical activity has been well documented (Ewing and Cervero 2010; McCormack and Shiell 2011; Saelens and Handy 2008). Specifically, residents living in highwalkable neighborhoods (i.e., higher residential density, increased street connectivity, good public transportation access) walk more and drive less than residents living in less walkable neighborhoods (i.e., low residential density and homogeneous land use) (Frank et al. 2005; Owen et al., 2007). Associating the built environment and health outcomes is more complex, but studies show inverse relationships between neighborhood walkability and obesity (Papas et al. 2007), cardiovascular disease ( $\mathrm{Li}$ et al. 2009), and type 2 diabetes (Booth et al. 2013). Nestled within these relationships is the concept of residential "self-selection," where individuals tend to select neighborhoods that support their physical activity and travel preferences (Frank et al. 2007; Sallis et al. 2009). Alongside this body of research, several studies have examined the concept of "residential mismatch"-the discrepancy between neighborhood preferences and the built environment of the neighborhood in which people reside (e.g., Cao 2008; De Vos et al. 2012; Howley 2009; Levine and Frank 2007; Levine, Inam, and Torng 2005; Schwanen and Mokhtarian 2004). Few studies have combined self-selection with travel- and health-related outcomes, and few have focused on this question within the context of a smaller community, where choices for residential environment are more constrained.

Preferences for walkable or suburban neighborhood designs have been shown to be a significant predictor of the transport mode choice for commuting, even when mode choice and neighborhood preference are "mismatched" (Schwanen and Mokhtarian 2005). Schwanen and Mokhtarian (2005) showed that people who preferred suburban residential environments but lived in walkable neighborhoods (i.e., mismatched) were more likely to commute by car than those who preferred and lived in walkable neighborhoods. However, they were less likely to commute by car than people who preferred and lived in suburbia. Frank et al. (2007) built on this research by objectively measuring the walkable or suburban character of residential environments and investigating how (mis)matching with one's preferred residential environment predicted walking behavior and health outcomes. Frank et al. (2007) found that individuals who lived in suburban environments were nearly twice as likely to be obese (i.e., body mass index 
$[\mathrm{BMI}] \geq 30 \mathrm{~kg} / \mathrm{m} 2$ ) as respondents who lived in a walkable neighborhood, regardless of their preference for walkable neighborhoods. The link between obesity and neighborhood walkability has since been demonstrated across different large Canadian cities (Frank et al. 2015), at the provincial scale (e.g., Chiu et al. 2015), as well as in New Zealand (Badland et al. 2012) and Australia (Kamruzzaman et al. 2013).

Given the potential for the built environment to shape population health outcomes through supporting active travel, understanding the demand for different types of neighborhood environments is at the core of urban planning and real estate market research (Myers and Gearin 2001; Levine, Inam, and Torng 2005). Residential location choice is based on a variety of tradeoffs including costs, property characteristics, and transportation accessibility. The relative importance of these factors varies according to individual sociodemographic factors (Kim, Pagliara, and Preston 2005). Perhaps most interesting is that preference for more compact, walkable neighborhoods is becoming more prevalent, even when this entails losing desirable aspects of low-density environments such as larger lots and single-family housing (Handy et al. 2008; Levine and Frank 2007). This shift in preference is attributable to several converging factors, including aging populations, smaller households, rising fuel costs, traffic congestions, and increased health and environmental concerns with suburban areas (Frank et al. 2015; Litman 2009; Myers and Gearin 2001).

Several gaps remain within residential preference research. First, the relationships between walkability, residential preference, and travel behavior have yet to be examined in the context of midsized city regions, particularly those exhibiting limited environmental variability. Most travel behavior studies are based on studies of households in large metropolitan regions of more than one million people (e.g., Bunting et al. 2007; Frank et al. 2015). Applying these findings to midsized cities could be problematic because travel dynamics and residential settlement patterns may be considerably different. Midsized cities typically have less developed mass transit systems than large cities, and few have rail rapid-transit lines that attract "choice riders" (i.e., those who have access to personal vehicles but opt for public transit). The configuration of midsized cities, whose centers are typically more accessible by car from surrounding communities and suburbs, differs from large cities, where car mobility within the downtown core can be more difficult. While commute time is a significant predictor of residential location choice within large metropolitan areas (Cervero 1996; Levine 1998), it is unclear whether this relationship holds for midsized regions, where trip distances and travel times are shorter and less variable across the population. We, therefore, ask whether residential location choice and its level of matching with residents' neighborhood preferences significantly affect travel patterns and health outcomes in midsized cities.

A second research gap is the lack of distinction between utilitarian walk trips and recreational walk trips among existing mismatch studies and in the few transportation studies situated in midsized city regions. Among mismatch studies, Schwanen and Mokhtarian (2005)investigated commute times but not walking behavior. In their Atlanta-based study, Frank et al. (2007) separated recreational (discretionary) from utilitarian (nondiscretionary) walk trips. They found that demographic variables, higher household income, and greater importance of nonmotorized selection and greater walkability predicted the likelihood of any utilitarian walk trips. Participants who reported self-selecting to live in a walkable place had significantly higher odds 
of recreational walking. Studies of the built environment and travel behavior in medium-sized city regions, such as Sultana and Weber (2007) and Maoh and Tang (2012), have also focused on single occupancy vehicle use and commuting distances rather than on walking behavior. Both recreational and utilitarian walk trips contribute to the amount of physical activity that people undertake. Built environment and attitudinal factors evidently have different relationships with recreational versus utilitarian walking (Frank et al. 2007; Giles-Corti et al. 2005; McCormack et al. 2012; Pikora et al. 2003), so we risk biasing the effects of the built environment if these two forms of walking behavior are not distinguished from one another. This could be problematic for planning strategies in midsized cities where the variability in built environment is generally low.

Finally, there has been a long-held assumption within planning and epidemiological circles that more walkable or cyclable neighborhoods can result in lower obesity rates due to higher calorific burning (Berke et al. 2007; Rundle et al. 2008). This is supported by evidence that individuals living in high-walkability areas are less likely to be obese than those living in low-walkability areas (e.g., Frank et al. 2015, 2007). Indeed, Kowaleski-Jones et al. (2018) showed that residential selection bias in cross-sectional studies has led to underestimations of the association between walkability and obesity. However, the concept of "self-selection" suggests that individuals may choose their neighborhood based on how it can support their physical activity and travel preferences (Sallis et al. 2009). Causal evidence on the nature of these observed associations is limited. One study suggests that effects of neighborhood planning and design could in some cases be premised on flawed principles (Creatore et al. 2016). Evidence reviewed above suggests that preferences and environmental features have independent associations with active transportation. Creating more walkable environments to meet their growing demand (Pivo and Fisher 2011) will likely attract those that prefer living in walkable places, thus resulting in increased walking among some population groups.

With the stated research gaps in mind, we explore how neighborhood preferences and environments collectively and independently predict walking behavior and obesity rates in the region of Waterloo, Ontario. We use a household survey of residential preferences and an index measure of the pedestrian and built environment to answer three questions:

1. What types of neighborhoods do midsized city region residents prefer: walkable or cardependent neighborhoods?

2. How well matched are people's neighborhood preferences to their actual residential environments?

3. Do neighborhood preferences, or the degree of match between preferences and actual residential environments, significantly predict people's obesity levels or the frequency that they engage in recreational and utilitarian walk trips?

Findings will contribute to our understanding of how the built environment and residential preferences relate to travel patterns and predictors of health outcomes in midsized city regions. 


\section{Methods}

\subsection{Study area}

This study of Waterloo Region in Ontario, Canada, includes the cities of Waterloo, Kitchener, and Cambridge. The study area is home to approximately 530,000 people and has a population density of 390.9 inhabitants per square kilometer (Statistics Canada 2017). The Waterloo Region is among the fastest growing areas in Southern Ontario, with a population expected to reach 642,000 by 2031 (Region of Waterloo Public Health 2017). The area is also characterized by an aging population and large number of postsecondary students, which, in conjunction with predicted population growth, will play an important role in future residential and transportation infrastructure decisions.

As expected, Table 1 shows that the Waterloo Region has considerably lower residential densities and retail floor area ratios (FAR) than the City of Toronto (population 2.8 million) or the City of Vancouver (population 650,000), two large Canadian cities for which walkability index data were available (Frank et al. 2015). The Waterloo Region also has lower variability in net residential density and retail FAR compared with Toronto and Vancouver. Reflective of its urban form, transportation in the Waterloo Region is dominated by the car. A new rail system known as the "ION" is being built to support a more compact urban form. Private vehicles are currently the dominant mode choice for commuters at 88 percent of trips (Region of Waterloo 2017), substantially higher than the Ontario average (79\%) and about 30 percent higher than in the nearby City of Toronto (Table 2).

\begin{tabular}{|c|c|c|c|c|}
\hline & Quartile & Waterloo Region & City of Toronto & City of Vancouver \\
\hline \multirow{4}{*}{ 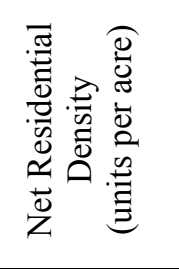 } & Q1 & 7.2 & 10.7 & 14.1 \\
\hline & $\begin{array}{c}\mathrm{Q} 2 \\
\text { (median) }\end{array}$ & 9.1 & 16.4 & 18.3 \\
\hline & Q3 & 12.0 & 26.3 & 38.3 \\
\hline & Max & 46.0 & 455.0 & 209.9 \\
\hline \multirow{4}{*}{ 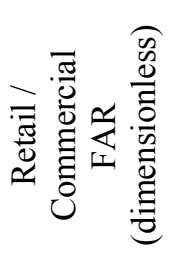 } & Q1 & 0.16 & 0.26 & 0.55 \\
\hline & $\begin{array}{c}\mathrm{Q} 2 \\
\text { (median) }\end{array}$ & 0.25 & 0.35 & 0.73 \\
\hline & Q3 & 0.33 & 0.58 & 0.88 \\
\hline & Max & 1.60 & 1.94 & 2.88 \\
\hline
\end{tabular}

Table 1. Variability in selected built environmental characteristics (minimum for all characteristics is 0), for Waterloo Region, the City of Toronto and City of Vancouver. Data were derived using methods described in main text.

The urban structure of the Waterloo region is considered typical of many mid-sized city regions in Canada and the U.S: low in density, dispersed in its trip destinations, and car-dependent in nature (Bunting et al. 2007). The city centre remains very accessible by car, with free parking and relatively low travel times, which acts to reinforce car dependency rather than encouraging a switch to alternate transport modes. As such, the findings from a Waterloo region study are likely to be applicable to many other mid-sized city regions across North America. 


\begin{tabular}{|l|l|l|l|}
\hline & \multicolumn{1}{|c|}{ Waterloo Region } & \multicolumn{1}{c|}{ City of Toronto } & \multicolumn{1}{c|}{ Ontario } \\
\hline Private vehicle (\%) & 88.0 & 56.0 & 79.0 \\
\hline Public transit (\%) & 4.6 & 34.0 & 13.0 \\
\hline Walking or bicycle (\%) & 6.8 & 9.0 & 7.0 \\
\hline
\end{tabular}

Table 2. Mode of transportation to work for Waterloo Region, the City of Toronto and Ontario. Source: Region of Waterloo, 2017.

\subsection{Data Sources}

Data used in this study were collected as part of the Neighborhood Environments in Waterloo Region: Patterns of Transportation and Health (NEWPATH) project between May 2009 and August 2010. Participation in the NEWPATH study was limited to households residing in the three cities of Kitchener, Waterloo, and Cambridge. A stratified sampling procedure was employed (Thompson et al. 2013), with the goal of recruiting a representative sample of the population with respect to household size, income levels, and the walkability level of the neighborhood in which people resided. The sample was also allocated in such a way as to give high statistical power to comparisons across walkability levels. The design was similar to the "orthogonal" approach for neighborhood level sampling in Frank et al. (2010), where high- and low-walkability and high- and low-income categories were crossed with each other to produce a list of block groups that fit into one of four quadrants (i.e. low walkability and low income, low walkability and high income, high walkability and low income, high walkability and high income). Participating households were assigned to one of two groups: (i) a "complex" group, who were asked to wear accelerometers and to complete travel diaries for two days, including a record of food purchasing, and (ii) a "simple" group, who were asked to complete travel diaries for two days, but without food purchasing records. Both types of households completed a recruitment questionnaire and attitude and behavior questionnaires which asked about neighborhood preferences and food shopping patterns. Households were recruited in day-pairs (pairs of consecutive days), randomly assigned across all days of the week. Participants from both groups were included in the study sample, yielding a total sample size of 2,597 adults.

\subsection{Measures}

\subsubsection{Demographic and Household Variables}

The following covariates were controlled for in this study: gender, age, household income and vehicle ownership. All variables were self-reported. Vehicle ownership was recorded as the number of vehicles owned by household members, and categorized as $0,1,2,3$ or $4+$ cars. Household income was recorded and used in the analysis as a categorical variable with the following categories: $<\$ 35,000, \$ 35,000-\$ 85,000$, and $>\$ 85,000$.

\subsubsection{Travel Behavior and Obesity}

Transportation measures from the two-day travel diary included: walking at least once over the two-day period for any purpose, walking at least once over the two-day period for recreational purposes, and walking at least once over the two-day period for utilitarian purposes. Trips were 
coded as recreational if they were for personal entertainment, leisure activities (including leisurely walking), walking for exercise and sports. Trips coded as utilitarian included work and school trips, banking, medical appointments and attending public events. Appendix 1 provides a complete list of all activities in each trip type. Vehicle travel was recorded as annual household vehicle kilometers travelled (VKT). Body mass index (BMI) was calculated using self-reported height and weight. Participants with BMI values $\geq 30.0 \mathrm{~kg} / \mathrm{m}^{2}$ were classified as obese.

\subsubsection{Neighborhood Walkability}

We used a "walkability index", calculated using a previously validated approach (Frank et al. 2010) based on a pedestrian-specific street network, to characterize the built environment within $1 \mathrm{~km}$ (approximating to 10-15 mins' walk) of each participant's home postal code. Briefly, the walkability index was calculated by summing the Z-scores for four objectively measurable features of the built environment within a $1 \mathrm{~km}$ network buffer (measured in ArcGIS) of the centroid of each of the 8,425 unique postal codes in Waterloo Region (Figure 1). The four features contributing to the walkability index are:

- Net residential density (the number of residential units per residential acre);

- Degree of land use mix (the evenness of distribution of floor space across 6 categories of land use);

- Retail density (ratio of retail floor area to retail land area);

- Street connectivity (number of intersections within the buffer divided by the buffer area in square kilometers).

The street connectivity Z-score was weighted by a factor of two in the walkability index (Frank et al., 2010), based on prior evidence showing the strong influence of street connectivity on nonmotorized travel choice (Saelens et al., 2003). Positive walkability index values are associated with denser, pedestrian-friendly, and transit-oriented communities, while negative walkability index values are associated with more car-dependent, suburban neighborhoods. The walkability index developed for this study represents an improvement over Frank et al. (2010), because in addition to the conventional street network used to calculate the $1 \mathrm{~km}$ network buffer, we also include off-street trails and pathways. The inclusion of these off-street pedestrian pathways resulted in a $23 \%$ average increase in intersection density across the study area. Since off-street pedestrian paths are heterogeneously distributed throughout the region, their inclusion results in a more robust walkability index that better captures local pedestrian environments. Participants were assigned the neighborhood walkability index value associated with their home postal code and grouped into quartiles of neighborhood walkability (low, medium-low, medium-high, and high walkability), which were based on the full range of walkability index values observed in Waterloo Region. Since Z-scores are used to normalize the features contributing to the walkability index in a given region, it is not possible to directly compare walkability in Waterloo to that of other cities. Instead, the index allows us to objectively quantify the relative spatial differences in walkability across Waterloo itself.

Our walkability surface was calculated using 2012 built environment data (i.e. shortly after completion of the travel surveys in 2009-10). However, there has been relatively little change in walkability in the region of Waterloo over the last decade. Although calculated using a different 
measure of walkability, analysis by the Region of Waterloo (2016) shows that the proportions of the population living in low, medium and high walkable areas remained stable over the period of 2011-16. This minimises the issue of coupling our data across slightly different time periods, and ensures that results from our analyses remain relevant and informative for present-day planning decisions in the region.

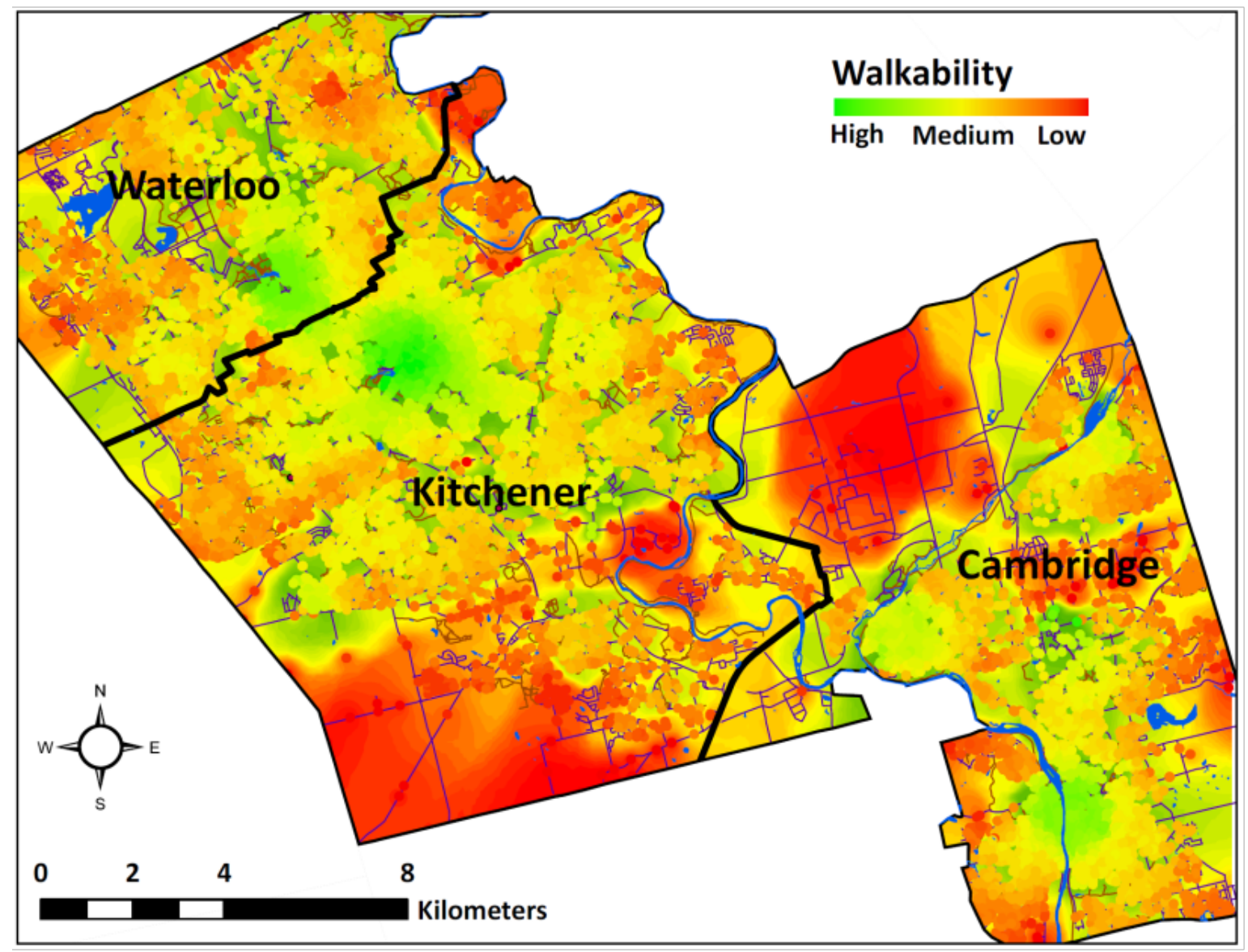

Figure 1: Walkability index of postal codes in Waterloo Region $(\mathrm{n}=8,425)$

\subsubsection{Neighborhood Preference}

We used an adapation of a previously-developed residential preference survey instrument (Levine \& Frank, 2007) to investigate the level of demand for walkable versus car-dependent neighborhood types. The survey instrument also probed which design features of the residential environment were most highly valued by study participants. Seven illustrated neighborhood scenarios were presented as a trade-off between a car-dependent neighborhood environment and a walkable neighborhood, showing contrasting aspects of neighborhood design and travel convenience inherent to either neighborhood type (Figure 2). Participants responded with their preference 
towards Neighborhood A versus Neighborhood B using an 11-point Likert scale. Extraneous factors that might affect a household's decision-making, such as job availability, housing costs, and school quality were explicitly stated to be equivalent between the two scenarios to facilitate the comparison. Some research has shown that highly walkable neighborhoods result in increased property prices (Pivo \& Fisher, 2010) and land prices (Rauterkus \& Miller, 2011), which may not be offset by transportation savings. However, Boyle et al. (2014) showed that the impact of walkability on housing value becomes statistically insignificant at the margin, when controlling for heteroscedasticity and neighborhood fixed effects. We acknowledge that potential trade-offs between walkability and cost may exist, but for the purposes of this study we chose to maintain cost parity amongst scenarios.

The seven trade-off scenarios included:

1. Separated versus integrated residential-commercial areas;

2. Lower residential density (e.g. larger lot size) versus shorter commute distance;

3. Urban vitality versus low density, single-use neighborhoods;

4. Shorter commute distance versus quieter cul-de-sac streets with minimal traffic;

5. Smaller homes and availability of active transportation choices versus larger homes in cardependent neighborhoods;

6. More space for walking and cycling versus more space for cars

7. Busier streets with alternatives to car travel versus neighborhood privacy (cul-de-sac layout with minimal car and pedestrian traffic).

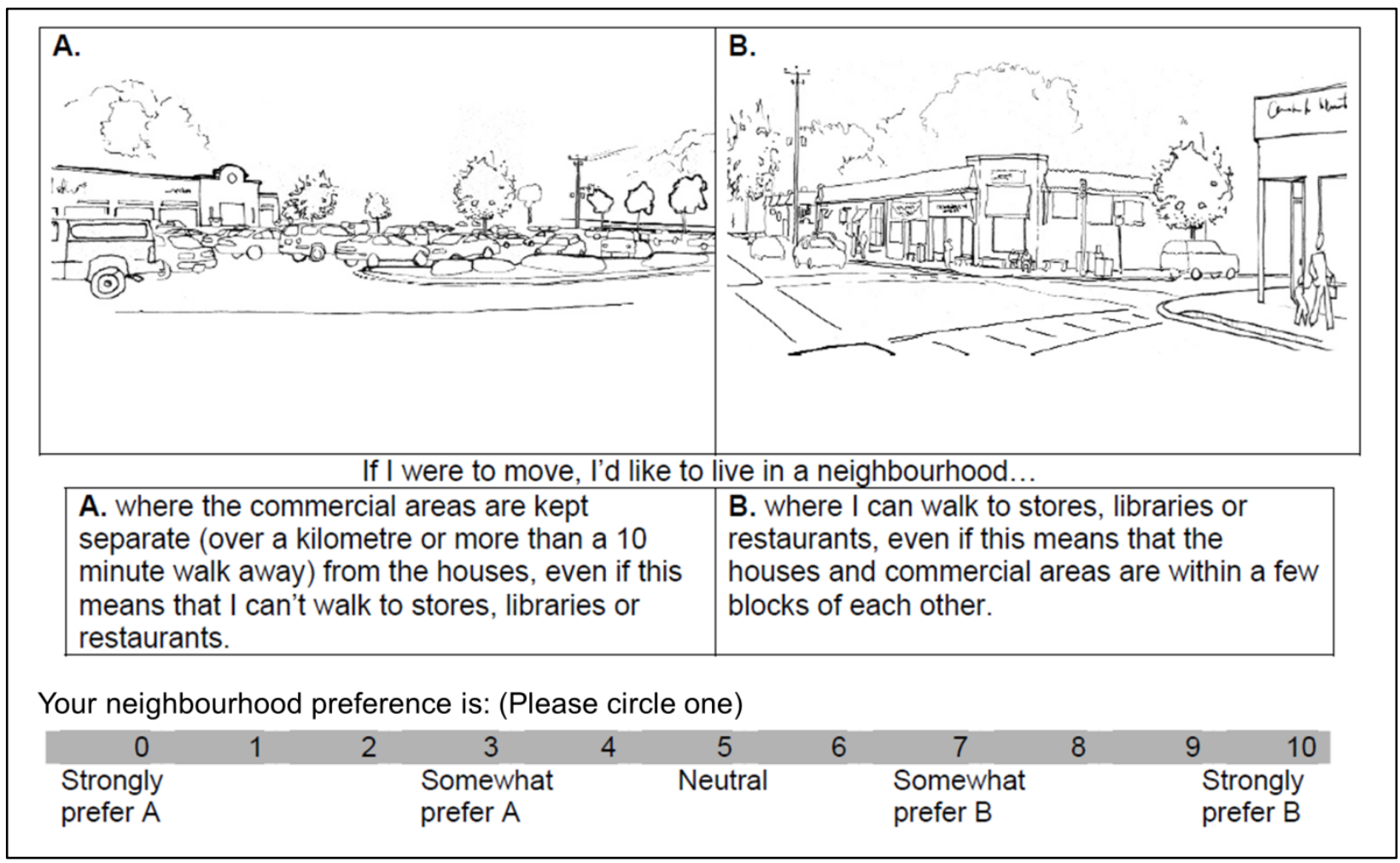

Figure 2. Neighborhood trade-off scenario example: preferences for separated versus integrated residentialcommercial areas 
Likert scale responses for each of the seven trade-off scenarios were aggregated into three broader categories to assess participant attitudes towards specific attributes of walkable versus cardependent residential environments:

- $\quad 0-2$ : Strongly prefer car-dependent places

- 3-7: Neutral

- 8-10: Strongly prefer walkable places

A composite measure of neighborhood preference per participant was calculated from the paired trade-offs using principal component analysis (PCA) to extract a factor with which the observed variables are highly correlated. Exploratory analysis revealed that all trade-off questions were highly correlated $(>0.7)$ with the neighborhood preference component, except for the trade-off evaluating preference for space for walking and cycling versus cars (trade-off number 6). Preliminary PCA also revealed this trade-off was poorly represented by the extracted component, so this particular survey question was excluded from the final PCA. Low loading on this trade-off may relate to the fact that, unlike for the other trade-off questions, the implied preferences are directly related to people's preconceived attitudes towards the use of space in their neighbourhood (Pender, 2012). Table 3 shows the component loadings for each trade-off question used in the following analyses. Based on a Cronbach's alpha value of 0.864 , we conclude that the six input variables are internally consistent. The neighborhood preference factor explained $59.7 \%$ of variance in the data and component loadings ranged from $0.720-0.825$.

\begin{tabular}{|l|c|}
\hline \multicolumn{1}{|c|}{ Trade-off scenario } & \multicolumn{1}{|c|}{$\begin{array}{c}\text { Neighborhood } \\
\text { preference } \\
\text { component loading }\end{array}$} \\
\hline $\begin{array}{l}\text { 7. Busier streets with alternatives to car travel versus neighborhood } \\
\text { privacy (cul-de-sac layout with minimal car and pedestrian traffic). }\end{array}$ & 0.825 \\
\hline $\begin{array}{l}\text { 4. Shorter commute distance versus quieter cul-de-sac streets with } \\
\text { minimal traffic }\end{array}$ & 0.792 \\
\hline $\begin{array}{l}\text { 5. Smaller homes and availability of active transportation choices } \\
\text { versus larger homes in car-dependent neighborhoods; }\end{array}$ & 0.778 \\
\hline 3. Urban vitality versus low density, single-use neighborhoods & 0.761 \\
\hline $\begin{array}{l}\text { 2. Lower residential density (e.g., larger lot size) versus shorter } \\
\text { commute distance }\end{array}$ & 0.757 \\
\hline 1. Separated versus integrated residential-commercial areas & 0.720 \\
\hline
\end{tabular}

Table 3. Neighborhood preference principal component factor loadings.

Each participant was assigned a continuous neighborhood preference score based on the summed product of their Likert scale response to each trade-off multiplied by the principal component factor loading from Table 3. The neutral position between preference for a pedestrian/transitoriented neighborhood versus preference for a car dependent neighborhood was set at zero by normalizing the neighborhood preference factor. A positive score indicates preference for a pedestrian/transit-oriented neighborhood, while a negative score indicates preference for a cardependent neighborhood. Participants were then grouped into quartiles of neighborhood preference (low, medium-low, medium-high, and high walkability), resulting in an equal number of participants in each preference quartile. 


\subsubsection{Neighborhood Concordance}

Alignment between neighborhood preference and existing neighborhood walkability was evaluated by jointly considering the neighborhood preference score and home postal code walkability rating for each participant. Participants were divided into four groups classifying them as either "matched" or "mismatched" with their preference and current neighborhood environment:

- Quadrant 1: [mismatched] Prefer high walkability, live in low walkability;

- Quadrant 2: [matched] Prefer high walkability, live in high walkability;

- Quadrant 3: [mismatched] Prefer low walkability, live in high walkability;

- Quadrant 4: [matched] Prefer low walkability, live in low walkability.

A zero value for both subjectively-reported neighborhood preference and objectively-measured walkability index was used as the breakpoint between high versus low walkability.

\subsection{Statistical Analyses}

To isolate the effect of the built environment on behavior from attitudinal predisposition, Chisquare analysis assessed whether there was a significant difference in the likelihood of walking for all purposes, utilitarian walking, recreational walking, and obesity levels among participants sharing similar preferences but living in different types of neighborhoods. That is, comparisons were made between the following groups:

- Participants who prefer high walkability, but live in low walkability versus those who prefer high walkability and live in high walkability (Quadrant 1 vs. Quadrant 2);

- Participants who prefer low walkability, but live in high walkability versus those who prefer low walkability and live in low walkability (Quadrant 3 vs. Quadrant 4).

Using the same groupings, ANOVA analyses assessed whether there was a significant difference in walk trip frequency for all trip purposes, utilitarian walking and recreational walking. We also assessed whether there was a significant difference in annual household VKT.

Separate logistic regression analyses were performed to predict the likelihood that participants reported walking for any purpose, the likelihood of reporting utilitarian walking, the likelihood of reporting any recreational walking, and obesity, when controlling for gender, age, household income, and vehicle ownership. Models were designed to identify the independent relationship with demographic factors, neighborhood walkability, and neighborhood preference. Model fit was assessed using the Hosmer-Lemeshow test.

\section{Results}

\subsection{Participant Characteristics}

Summary socio-demographic and travel characteristics of the study sample are reported in Table 4. Variables describing income, education level, presence of children, household size, and immigration are all comparable to those found in the general Waterloo Region population. The sample has a larger proportion of females, a higher mean age and more people living in singledetached and owned dwellings compared to the 2016 census. Individuals with a university education are over-represented because of a deliberate oversampling of University of Waterloo students to address an under-representation of the student-aged population. Stratification of the 
sample by neighborhood preference quartile suggests that walkable neighborhoods are preferred by those with smaller households and fewer children, lower incomes, those born outside Canada, renters, and those with a higher level of education. These characteristics are likely related to the larger proportion of students living in the sampled households.

\begin{tabular}{|c|c|c|c|c|c|c|c|}
\hline & \multirow[b]{2}{*}{$\begin{array}{c}\text { Study } \\
\text { sample }^{1}\end{array}$} & \multirow[b]{2}{*}{$\begin{array}{c}\text { Waterloo } \\
\text { Region }^{2}\end{array}$} & \multicolumn{4}{|c|}{ Neighborhood Preference $^{3}$} \\
\hline & & & & $\begin{array}{c}\text { Low } \\
\text { Walkable } \\
\text { (Q1) }\end{array}$ & $\begin{array}{c}\text { Medium- } \\
\text { Low } \\
\text { Walkable } \\
\text { (Q2) } \\
\end{array}$ & $\begin{array}{c}\text { Medium- } \\
\text { High } \\
\text { Walkable } \\
\text { (Q3) } \\
\end{array}$ & $\begin{array}{c}\text { High } \\
\text { Walkable } \\
\text { (Q4) }\end{array}$ \\
\hline \multicolumn{2}{|l|}{ Age } & $48.7(15.1)$ & 39.1 & $46.3(13.7)$ & $48.4(14.2)$ & $48.6(15.3)$ & $49.7(15.8)$ \\
\hline \multicolumn{2}{|c|}{ Gender (female) } & $65.5 \%$ & $50.6 \%$ & $60.0 \%$ & $68.2 \%$ & $66.1 \%$ & $67.9 \%$ \\
\hline \multicolumn{2}{|c|}{ Born outside Canada (\%) } & $23.2 \%$ & $22.3 \%$ & $18.3 \%$ & $21.4 \%$ & $22.7 \%$ & $27.5 \%$ \\
\hline \multirow{3}{*}{ 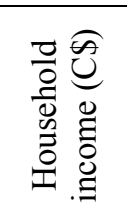 } & $<\$ 35,000$ & $21.1 \%$ & \multirow{3}{*}{$\$ 77,530^{4}$} & $12.7 \%$ & $19.4 \%$ & $22.2 \%$ & $26.8 \%$ \\
\hline & $\begin{array}{l}\$ 35,000- \\
\$ 85,000\end{array}$ & $38.6 \%$ & & $33.6 \%$ & $39.6 \%$ & $40.6 \%$ & $42.1 \%$ \\
\hline & $>\$ 85,000$ & $40.2 \%$ & & $53.7 \%$ & $41.0 \%$ & $37.3 \%$ & $31.1 \%$ \\
\hline \multicolumn{2}{|c|}{ Household size } & $2.6(1.3)$ & 2.6 & $2.9(1.3)$ & $2.7(1.3)$ & $2.5(1.3)$ & $2.2(1.2)$ \\
\hline \multicolumn{2}{|c|}{ Household with child (\%) } & $46.2 \%$ & $34.0 \%{ }^{5}$ & $55.2 \%$ & $52.0 \%$ & $44.2 \%$ & $33.6 \%$ \\
\hline \multicolumn{2}{|c|}{ Single-detached dwelling } & $71.3 \%$ & $55.6 \%$ & $82.1 \%$ & $77.6 \%$ & $68.7 \%$ & $58.6 \%$ \\
\hline \multicolumn{2}{|c|}{ Home owners } & $80.2 \%$ & $68.2 \%$ & $89.1 \%$ & $85.9 \%$ & $78.1 \%$ & $69.0 \%$ \\
\hline \multirow{2}{*}{ 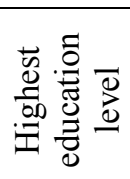 } & University & $41.5 \%$ & $23.3 \%$ & $38.6 \%$ & $34.1 \%$ & $41.2 \%$ & $54.9 \%$ \\
\hline & High school & $23.2 \%$ & $28.9 \%$ & $20.7 \%$ & $26.5 \%$ & $22.4 \%$ & $19.6 \%$ \\
\hline \multicolumn{2}{|c|}{ Employed } & $61.8 \%$ & $64.2 \%$ & $69.5 \%$ & $62.4 \%$ & $59.9 \%$ & $58.1 \%$ \\
\hline
\end{tabular}

Table 4. Descriptive statistics for demographic variables stratified by neighborhood preference. Values of variables show mean (standard deviation in brackets) or percentage where appropriate.

1. $n=2,597$

2. Statistics Canada 2016 Community Profile

3. Q1: $\mathrm{n}=605 ; \mathrm{Q} 2: \mathrm{n}=604 ; \mathrm{Q} 3: \mathrm{n}=604 ; \mathrm{Q} 4: \mathrm{n}=604$

4. Median before tax income of all private households

5. Households containing a couple (married or common-law) with children

Travel behavior characteristics for each neighborhood preference quartile are shown in Table 5. Within the two-day travel diary period, $29.7 \%$ of individual participants made at least one walking trip during the two-day travel diary period, which is reflective of the car-dependent design of the region. The majority of walking trips were utilitarian, with $22.7 \%$ of individuals making at least one utilitarian walking trip, and $11.3 \%$ making at least one recreational walking trip. On average, households drove 25,600 kilometers per year. A greater number of walk trips, fewer VKT, and lower obesity levels were observed among participants preferring more walkable neighborhoods. 
Notably, the proportion of individuals in the sample who are obese $(32.8 \%)$ is substantially higher than the regional average of $23.7 \%$ (Navaneelan and Janz 2014).

\begin{tabular}{|l|c|c|c|c|c|c|}
\hline & \multicolumn{2}{|c|}{ Study sample } & \multicolumn{3}{c|}{ Neighborhood Preference $^{1}$} \\
\cline { 2 - 7 } & $\begin{array}{c}\text { Sample } \\
\text { size }\end{array}$ & Value & $\begin{array}{c}\text { Low } \\
\text { Walkable } \\
(\mathbf{Q 1 )}\end{array}$ & $\begin{array}{c}\text { Medium- } \\
\text { Low } \\
\text { Walkable } \\
(\mathbf{Q} 2)\end{array}$ & $\begin{array}{c}\text { Medium- } \\
\text { High } \\
\text { Walkable } \\
(\mathbf{Q})\end{array}$ & $\begin{array}{c}\text { High } \\
\text { Walkable } \\
(\mathbf{Q})\end{array}$ \\
\hline \% taking a walk trip & $\mathrm{n}=2,367$ & $29.7 \%$ & $14.5 \%$ & $20.5 \%$ & $35.8 \%$ & $48.1 \%$ \\
\hline \% taking utilitarian walk trip & $\mathrm{n}=2,238$ & $22.7 \%$ & $11.2 \%$ & $14.0 \%$ & $27.3 \%$ & $39.6 \%$ \\
\hline $\begin{array}{l}\text { \% taking recreational walk } \\
\text { trip }\end{array}$ & $\mathrm{n}=2,238$ & $11.3 \%$ & $3.5 \%$ & $7.9 \%$ & $13.0 \%$ & $21.7 \%$ \\
\hline Mean walk trips & $\mathrm{n}=703$ & $0.50(1.0)$ & $0.20(0.6)$ & $0.30(0.7)$ & $0.55(1.0)$ & $0.96(1.4)$ \\
\hline $\begin{array}{l}\text { Mean utilitarian walk trips } \\
\mathrm{nyyyyyy}\end{array}$ & $\mathrm{n}=508$ & $0.43(0.9)$ & $0.20(0.6)$ & $.25(0.7)$ & $0.50(1.0)$ & $0.80(1.2)$ \\
\hline Mean recreational walk trips & $\mathrm{n}=254$ & $0.12(0.4)$ & $0.04(0.2)$ & $0.08(0.3)$ & $0.14(0.4)$ & $0.23(0.5)$ \\
\hline $\begin{array}{l}\text { Annual household VKT } \\
\text { thousands) }\end{array}$ & $\mathrm{n}=2,594$ & $25.6(27.8)$ & $33.6(29.9)$ & $26.5(25.4)$ & $24.0(26.5)$ & $19.2(28.2)$ \\
\hline \% Obese $\left(\geq 30 \mathrm{~kg} / \mathrm{m}^{2}\right)$ & $\mathrm{n}=2,006$ & $32.8 \%$ & $39.1 \%$ & $35.1 \%$ & $30.7 \%$ & $26.0 \%$ \\
\hline
\end{tabular}

Table 5. Walk trips over two-day travel diary period, VKT, and obesity prevalence by neighborhood preference quartile. Values of variables show mean (standard deviation in brackets) or percentage where appropriate.

1. Q1: $n=605 ; \mathrm{Q} 2: \mathrm{n}=604 ; \mathrm{Q} 3: \mathrm{n}=604 ; \mathrm{Q} 4: \mathrm{n}=604$

\subsection{Neighborhood Preference}

Across the seven neighborhood trade-off scenarios, $21-47 \%$ of respondents expressed strong preference for the pedestrian/transit-oriented development option (Table 6). In contrast, strong preference for more car-dependent options was reported by 4-32\% of participants. More space for walking and cycling was the pedestrian-oriented design feature with the most support (47\%), followed by a desire for more integrated residential and commercial areas (41\%), and smaller homes with more active transportation options (40\%). Trade-offs that presented substantial deviations from traditional suburban development received the lowest support for the walkable trade-off option. For example, trade-off number 3 (choosing between a lively neighborhood with a variety of housing types on various sized lots versus low density, single-use neighborhoods with larger lots) had the highest proportion of participants strongly preferring the car-dependent option $(32 \%)$. 


\begin{tabular}{|l|l|c|c|}
\hline \multicolumn{1}{|c|}{ Trade-off scenario } & $\begin{array}{c}\text { Deviation from } \\
\text { suburban } \\
\text { pattern }\end{array}$ & $\begin{array}{c}\text { \% strongly } \\
\text { preferring } \\
\text { pedestrian-oriented } \\
\text { development (8-10) }\end{array}$ & $\begin{array}{c}\text { \% strongly } \\
\text { preferring car- } \\
\text { dependent } \\
\text { environment (0-2) }\end{array}$ \\
\hline $\begin{array}{l}\text { 1. Separated versus integrated residential- } \\
\text { commercial areas }\end{array}$ & Mixed uses & 40.5 & 14.4 \\
\hline $\begin{array}{l}\text { 2. Lower residential density (e.g., larger lot } \\
\text { size) versus shorter commute distance }\end{array}$ & Smaller lots & 34.4 & 16.8 \\
\hline $\begin{array}{l}\text { 3. Urban vitality versus low density, single- } \\
\text { use neighborhoods }\end{array}$ & $\begin{array}{l}\text { Higher densities } \\
\text { and mixed uses }\end{array}$ & 21.0 & 32.4 \\
\hline $\begin{array}{l}\text { 4. Shorter commute distance versus quieter } \\
\text { cul-de-sac streets with minimal traffic }\end{array}$ & $\begin{array}{l}\text { Presence of } \\
\text { through traffic }\end{array}$ & 34.9 & 14.9 \\
\hline $\begin{array}{l}\text { 5. Smaller homes and availability of active } \\
\text { transportation choices versus larger homes in } \\
\text { car-dependent neighborhoods }\end{array}$ & Smaller houses \\
\hline $\begin{array}{l}\text { 6. More space for walking and cycling versus } \\
\text { more space for cars }\end{array}$ & Narrower streets & 39.7 & 4.2 \\
\hline $\begin{array}{l}\text { 7. Busier streets with alternatives to car travel } \\
\text { versus neighborhood privacy (cul-de-sac } \\
\text { layout with minimal car and pedestrian } \\
\text { traffic). }\end{array}$ & $\begin{array}{l}\text { Connected street } \\
\text { network }\end{array}$ & 35.3 & 14.2 \\
\hline
\end{tabular}

Table 6. Preference levels for trade-off scenarios.

\subsection{Assessing Mismatch between Neighborhood Preference and Neighborhood Design}

Figure 3 illustrates the distribution of survey participants across quadrants of neighborhood concordance. Participants whose current neighborhood is aligned with their preference $(64.2 \%$ of the study sample) are located in the upper-right and lower-left quadrants. The remaining 35.8\% are mismatched (21.2\% preferring high walkability but living in low walkability neighborhoods and $14.6 \%$ preferring car-dependent neighborhoods but living in a walkable neighbourhood). The relatively small number of participants living in very low walkability environments reflects the sparse populations of low-density areas. 


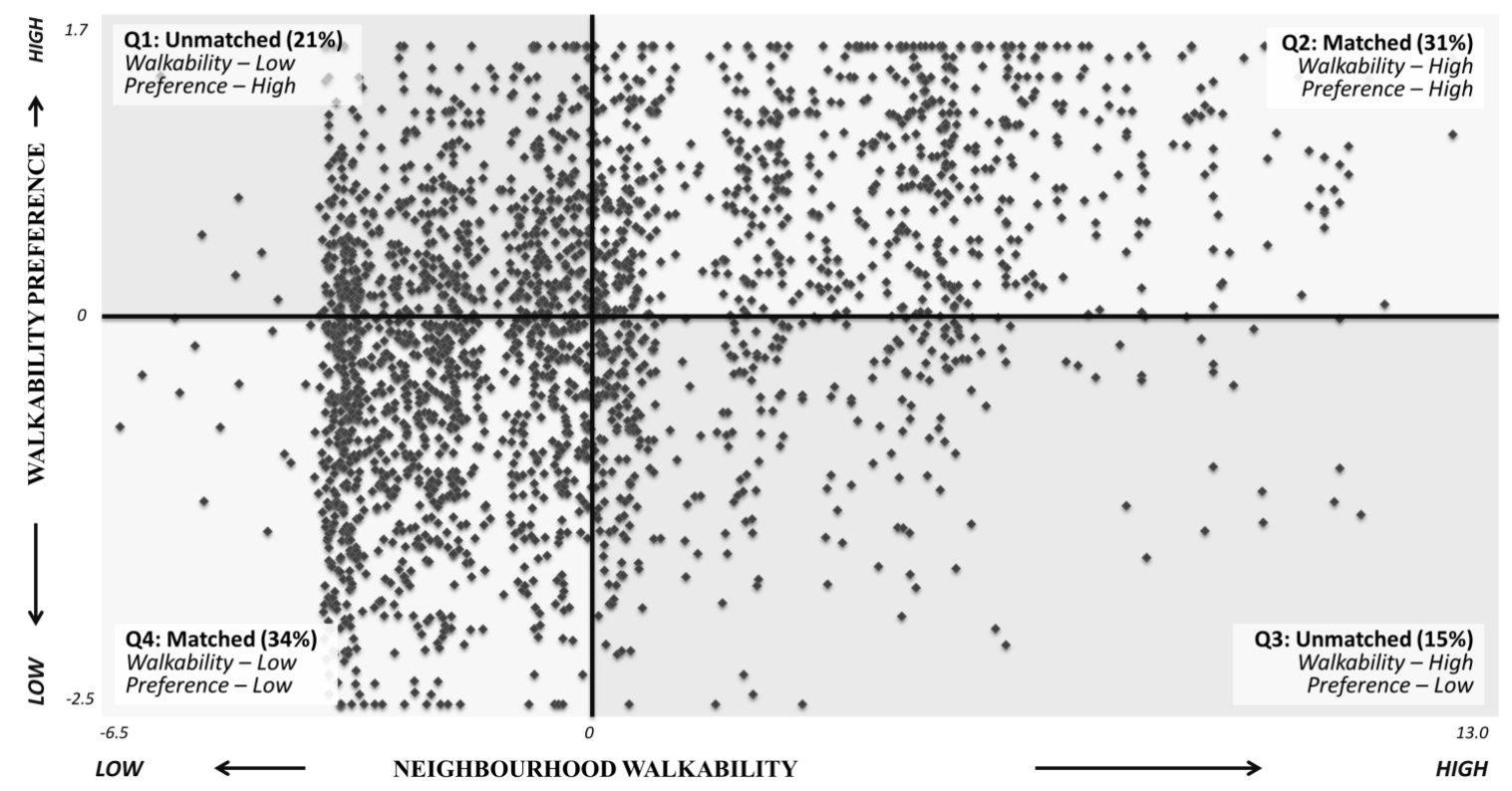

Figure 3. Quadrant chart showing objective neighbourhood walkability versus preference for neighbourhood walkability $(\mathrm{n}=2,397)$.

\subsection{Travel behavior and obesity}

By examining differences in travel behavior across the quadrants in Figure 3, it is possible to determine whether there is a joint effect of neighborhood preference and the built environment on travel behavior. Obesity prevalence and travel behavior for each concordance quadrant are shown in Table 7. The proportion of people preferring and living in a walkable community that take a walk trip (50.4\%) is almost double that of people who prefer a walkable environment but live in a low walkability neighbourhood (28.8\%). This confirms earlier findings from Frank et al. (2007). Similarly, those who prefer and live in a walkable neighborhood are significantly more likely to make a utilitarian trip (41.4\%) than those who are mismatched in a low walkability neighbourhood $(21.7 \%)$. The incidence of recreational walk trips was significantly higher for those who live in and prefer a high walkability neighborhood (23.3\%), compared to those who prefer a high walkability neighborhood but live in a low walkability environment $(9.0 \%)$. These findings contrast with those made by McCormack et al. (2012), who reported no significant difference in recreational walking behavior across different neighborhood environments. McCormack et al. (2012) alluded to various social differences across neighborhoods being responsible for their observed lack of difference, and concluded that supportive neighborhood built environments may be necessary, but alone insufficient, to increase recreational walking. 


\begin{tabular}{|l|r|r|r|r|}
\hline \multirow{2}{*}{\multicolumn{1}{|c|}{ Travel behaviour }} & \multicolumn{2}{c|}{$\begin{array}{c}\text { Neighborhood Preference: } \\
\text { High Walkability }\end{array}$} & \multicolumn{2}{c|}{$\begin{array}{c}\text { Neighborhood Preference: } \\
\text { Low Walkability }\end{array}$} \\
\cline { 2 - 5 } & $\begin{array}{c}\text { Q1. Unmatched } \\
\text { (live in low } \\
\text { walkability) }\end{array}$ & $\begin{array}{c}\text { Q2. Matched } \\
\text { (live in high } \\
\text { walkability) }\end{array}$ & $\begin{array}{c}\text { Q3. Unmatched } \\
\text { (live in high } \\
\text { walkability) }\end{array}$ & $\begin{array}{c}\text { Q4. Matched } \\
\text { (live in low } \\
\text { walkability) }\end{array}$ \\
\hline \% taking a walk trip & 28.8 & $50.4^{* * *}$ & 20.6 & 15.9 \\
\hline \% taking utilitarian walk trip & 21.7 & $41.4^{* * *}$ & 14.8 & 11.6 \\
\hline \% taking recreational walk trip & 9.0 & $23.3^{* * *}$ & 6.9 & 5.0 \\
\hline Number of walk trips ${ }^{2}$ & $1.4(1.0)$ & $2.0(1.3)^{* * *}$ & $1.4(0.9)$ & $1.4(0.8)$ \\
\hline Number of utilitarian walk trips ${ }^{3}$ & $1.7(0.9)$ & $2.0(1.0)^{*}$ & $1.7(0.8)$ & $1.8(0.8)$ \\
\hline Number of recreational walk trips ${ }^{4}$ & $1.0(0.5)$ & $1.1(0.6)$ & $1.0(0.4)$ & $1.1(0.4)$ \\
\hline Annual household VKT (thousands) & $27.0(30.0)$ & $18.1(24.8)^{* * *}$ & $25.1(25.1)$ & $32.1(28.4)^{* *}$ \\
\hline$\%$ obese $\left(\geq 30 \mathrm{~kg} / \mathrm{m}^{2}\right.$ ) & 30.2 & 28.2 & 38.3 & 36.0 \\
\hline
\end{tabular}

Table 7. Travel behavior by neighborhood concordance quadrant (standard deviation shown in brackets).

***significantly different $(\mathrm{p}<0.001)$ than unmatched quartile (Q1 vs. Q2; Q3 vs. Q4)

**significantly different $(\mathrm{p}<0.01)$ than unmatched quartile (Q1 vs. Q2; Q3 vs. Q4)

*significantly different $(\mathrm{p}<0.05)$ than unmatched walk quartile (Q1 vs. Q2; Q3 vs. Q4)

1. Q1: $n=508 ; \mathrm{Q} 2: \mathrm{n}=731 ; \mathrm{Q} 3: \mathrm{n}=351 ; \mathrm{Q} 4: \mathrm{n}=807$

2. Only participants reporting at least one walk trip over two day travel diary period

3. Only participants reporting at least one utilitarian walk trip over two day travel diary period

4. Only participants reporting at least one recreational walk trip over two day travel diary period

There was a significant difference between the annual household VKT for participants who preferred high walkability areas and those who preferred low walkability areas, whether mismatched or not. Schwanen and Mokhtarian (2005) observed similar behavior in the San Francisco Bay Area. Apart from VKT, travel behavior was similar among those who prefer a low walkability neighborhood, regardless of actual neighborhood walkability. These results suggest that for individuals who prefer low walkability neighborhoods, the built environment has little to no effect on behavior. In a mid-sized city region like Waterloo, a limited transit system, short distances to amenities and relatively little traffic congestion provide few incentives to walk among those who prefer suburban lifestyles, regardless of the built environment characteristics of their neighborhood. For those who prefer walkable neighborhoods, however, living in a low walkability neighborhood may restrict their ability to fulfil their preferences for active transportation.

To further explore these relationships, we created models to relate preferences and objective walkability to walking, and controlled for age, sex, household income and vehicle ownership in logistic regression models. Results of these models are presented in Table 8. Goodness of fit for all models was assessed using the Hosmer-Lemeshow test; all models yielded non-significant ( $p$ $>0.05)$ results, suggesting adequate fit. Even when controlling for socio-demographics and neighborhood preferences, objectively-measured neighborhood walkability was associated with higher rates of walking. Living in a high walkability neighborhood is associated with significantly greater odds of making at least one utilitarian (OR: 2.027, $\mathrm{p}<0.001)$ and recreational (OR: 2.357, $\mathrm{p}<0.001)$ walking trip compared to living in a low walkability area. This suggests that neighborhood walkability is supportive of active transportation, regardless of preference. A 
preference for more walkable neighborhoods is similarly associated with greater likelihood of walking. The odds of an individual making at least one recreational or utilitarian walking trip within the two-day period are, respectively, 3.1 times and 3.9 times higher for people preferring high walkability environments than those preferring low walkability neighborhoods.

Belonging to the highest household income group ( $>\$ 85,000 /$ year) increased the odds of an individual taking at least one utilitarian walking trip by $\sim 20 \%$ compared to the middle income reference group. However, there was no significant difference between low and middle income participants in terms of recreation walking trips. For all types of walking trip, increased age and above-average car ownership (3-4 vehicles) was associated with a lower likelihood of walking. Not unexpectedly, not owing a car was very strongly associated with walking: individuals in carless households were nearly 5 times as likely to take at least one walking trip as counterparts in a two-car household. Gender was not significant in any of the models.

Obesity was only significantly associated with people's neighborhood preferences. Individuals who preferred high walkability neighborhoods were roughly half as likely to be obese as those who preferred low walkability neighborhoods. However, actually living in a high walkability neighborhood was not significantly associated with lower levels of obesity, all else being equal. This is counter to the findings of previous epidemiological studies (e.g. Berke et al., 2007; Frank et al., 2007; Rundle et al., 2008) linking more walkable areas to higher calorific burning and thus lower obesity rates. Instead, the findings presented here for the Region of Waterloo suggest that obesity, which can be caused by a variety of lifestyle factors, may partly shape people's neighbourhood preferences in a case of 'self-selection': obesity can make moderate physical activity such as walking more difficult, making vehicle-based mobility more appealing to obese individuals.

In contrast, in their study of the much larger Atlanta metropolitan region, Frank et al. (2007) found that individuals living the highest walkability quartile were significantly less likely to be obese than those living in the lowest quartile. Frank et al. (2015) reported similar findings from a residential preference study conducted in the metropolitan region of Vancouver, Canada, which is characterized by large variability in the built environment. The discrepancies between our findings and those from Atlanta and Vancouver may be attributable to the low variability in the built environment observed in mid-sized cities such as those in the Waterloo Region. That is, whilst there may be as wide a range of attitudes towards walkable lifestyles in Waterloo Region as in cities like Atlanta and Vancouver, the difference in built environment between the top and bottom walkability quartiles may be considerably smaller than those found in larger city regions. 


\begin{tabular}{|c|c|c|c|c|c|}
\hline \multirow{2}{*}{\multicolumn{2}{|c|}{ Independent variable }} & \multicolumn{4}{|c|}{ Dependent variable } \\
\hline & & $\begin{array}{l}\text { Walked at } \\
\text { least once } \\
\text { over 2-day }^{\text {period }}{ }^{1}\end{array}$ & $\begin{array}{c}\text { At least one } \\
\text { recreational } \\
\text { walking trip } \\
\text { over 2-day }^{\text {period }} \\
\text { per }^{2}\end{array}$ & $\begin{array}{c}\text { At least one } \\
\text { utilitarian walking } \\
\text { trip over 2-day } \\
\text { period }^{3}\end{array}$ & $\begin{array}{c}\text { Participant is } \\
\text { obese }\left(\geq 30 \mathrm{~kg} / \mathrm{m}^{2}\right)^{4}\end{array}$ \\
\hline \multirow{2}{*}{\multicolumn{2}{|c|}{$\begin{array}{l}\text { Age } \\
\text { Sex (reference male) }\end{array}$}} & $0.983 * * *$ & $0.985 * *$ & $0.980 * * *$ & $1.010^{* *}$ \\
\hline & & 0.965 & 0.909 & 1.01 & 0.992 \\
\hline \multirow{3}{*}{ 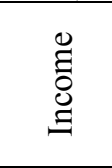 } & $<\$ 35,000$ & 0.986 & 0.695 & 0.906 & 0.909 \\
\hline & $\begin{array}{l}\$ 35,000- \\
\$ 85,000\end{array}$ & 1 & 1 & 1 & 1 \\
\hline & $>\$ 85,000$ & 1.215 & 0.947 & $1.395^{*}$ & 0.941 \\
\hline \multirow{5}{*}{ 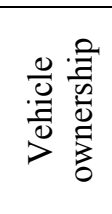 } & 0 vehicles & $4.809 * * *$ & $3.883^{* * *}$ & $5.494 * * *$ & 1.435 \\
\hline & 1 vehicle & $1.337^{*}$ & $1.487^{*}$ & $1.491^{* *}$ & 1.248 \\
\hline & 2 vehicles & 1 & 1 & 1 & 1 \\
\hline & 3 vehicles & 0.94 & 0.812 & 0.925 & 1.076 \\
\hline & $4+$ vehicles & 0.897 & 0.522 & 0.814 & 0.794 \\
\hline \multirow{4}{*}{ 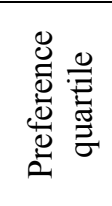 } & Low & 1 & 1 & 1 & 1 \\
\hline & Med-low & 1.358 & $1.97 *$ & 1.146 & 0.787 \\
\hline & Med-high & $2.679 * * *$ & $2.951 * * *$ & $2.425 * * *$ & $0.635^{* *}$ \\
\hline & High & $3.207 * * *$ & $3.914 * * *$ & $3.066^{* * *}$ & $0.487 * * *$ \\
\hline \multirow{4}{*}{ 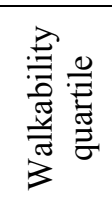 } & Low & 1 & 1 & 1 & 1 \\
\hline & Med-low & 1.162 & 1.202 & 1.081 & 1.022 \\
\hline & Med-high & 1.114 & 1.565 & 1.207 & 1.209 \\
\hline & High & $2.192 * * *$ & $2.357 * * *$ & $2.027 * * *$ & 0.938 \\
\hline
\end{tabular}

Table 8. Logistic regression model results for neighborhood preference and walkability. Reference values for each variable are as follows: income $(\$ 35,000-\$ 85,000)$, vehicle ownership (2 vehicles), preference quartile (low walkability), walkability quartile (low walkability).

$* \mathrm{p}<0.05, * * \mathrm{p}<0.01, * * * \mathrm{p}<0.001$

1. $\mathrm{n}=2,206$

2. $\mathrm{n}=2,085$

3. $\mathrm{n}=2,085$

4. $\mathrm{n}=1,872$

Finally, we perform ordinary least squares (OLS) regression to predict VKT (Table 9). In the first model, neighborhood concordance is used as a predictor of VKT. In the second model, neighborhood concordance is split to get a more nuanced understanding of whether preference or actual neighborhood walkability are better predictors of VKT. In both models, households owning fewer than 2 vehicles traveled significantly fewer vehicle kilometers than households owning 2 cars. Owning more than 2 cars was not significantly associated with greater VKT. As expected, higher income groups traveled more in cars than lower income groups, and women traveled less in cars than men. In the concordance model, only individuals who both preferred and lived in walkable neighborhoods showed significantly lower levels of annual VKT compared to those who preferred and lived in car-dependent neighborhoods. In the second model, preference for neighborhood environments was not a significant predictor of VKT, but living in the highest walkability quartile was associated with fewer VKT than living in the lowest walkability quartile. This suggests that changes to the built environment could help reduce the distance that individuals drive, irrespective of neighborhood preferences. This departs from the findings of Frank et al. 
(2007) for Atlanta, where both people's neighborhood preferences and where they lived had a significant effect on VKT. In mid-sized city regions such as Waterloo Region, there may therefore be a benefit to improving access to walkable neighborhoods. In the following Discussion section, we outline some of the policy implications that arise from our findings. 


\begin{tabular}{|c|c|c|c|}
\hline \multicolumn{2}{|c|}{ Independent variables } & $\begin{array}{c}\text { Model 1 } \\
\text { (concordance) }\end{array}$ & $\begin{array}{c}\text { Model 2 } \\
\text { (split concordance) }\end{array}$ \\
\hline \multicolumn{2}{|l|}{ Constant } & $11.145^{* * *}$ & $11.277^{* * *}$ \\
\hline \multicolumn{2}{|l|}{ Age } & -0.004 & -0.004 \\
\hline \multicolumn{2}{|c|}{ Sex (reference female) } & $-1.054 * * *$ & $-1.055 * * *$ \\
\hline \multirow{3}{*}{ 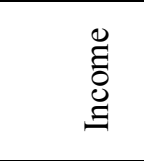 } & $<\$ 35,000$ & 0 & 0 \\
\hline & $\$ 35,000-\$ 85,000$ & $-0.665 * * *$ & $-0.650 * * *$ \\
\hline & $>\$ 85,000$ & $0.685^{* * *}$ & $0.666^{* * *}$ \\
\hline \multirow{5}{*}{ 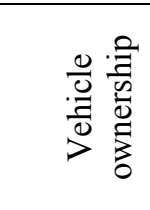 } & 0 vehicles & $-8.438 * * *$ & $-8.398 * * *$ \\
\hline & 1 vehicle & $-0.625 * * *$ & $-0.605 * * *$ \\
\hline & 2 vehicles & 0 & 0 \\
\hline & 3 vehicles & 0.19 & 0.176 \\
\hline & 4+ vehicles & 0.061 & 0.036 \\
\hline \multirow{4}{*}{ 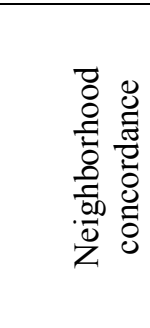 } & $\begin{array}{l}\text { Q1 (unmatched, prefer high } \\
\text { and live in low walkability) }\end{array}$ & -0.147 & - \\
\hline & $\begin{array}{l}\text { Q2 (matched, prefer and live } \\
\text { in high walkability) }\end{array}$ & $-0.300^{*}$ & - \\
\hline & $\begin{array}{l}\text { Q3 (unmatched, prefer low } \\
\text { and live in high walkability) }\end{array}$ & -0.199 & - \\
\hline & $\begin{array}{l}\text { Q4 (matched, prefer and live } \\
\text { in low walkability) }\end{array}$ & 0 & - \\
\hline \multirow{4}{*}{ 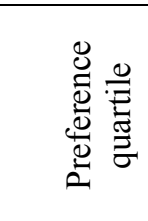 } & Low & - & 0 \\
\hline & Med-low & - & -0.151 \\
\hline & Med-high & - & -0.246 \\
\hline & High & - & -0.043 \\
\hline \multirow{4}{*}{ 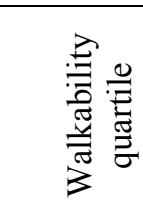 } & Low & - & 0 \\
\hline & Med-low & - & -0.058 \\
\hline & Med-high & - & -0.241 \\
\hline & High & - & $-0.393 *$ \\
\hline \multicolumn{2}{|l|}{$\mathrm{R}^{2}$} & 0.480 & 0.484 \\
\hline
\end{tabular}

Table 9. OLS regression predicting annual household VKT $(n=2,396)$. Reference values for each variable are as follows: income ( $\$ 35,000-\$ 85,000)$, vehicle ownership (2 vehicles), neighborhood concordance (Q4: matched, prefer and live in low walkability), preference quartile (low walkability), walkability quartile (low walkability).

${ }^{*} \mathrm{p}<0.05, * * \mathrm{p}<0.01, * * * \mathrm{p}<0.001$

\section{Discussion}

Findings from this study demonstrate that while the majority $(64.2 \%)$ of residents in the Waterloo Region live in a neighbourhood that matches their preference for walkability, there is still a substantial minority (35.8\%) whose walkability preferences are mismatched with their environment. This significant mismatch is important because our results suggest that, even when controlling for preferences, objective neighborhood walkability is associated with greater levels of both recreational and utilitarian walking behavior. Moreover, only individuals who prefer and live in walkable neighborhoods drive significantly less than people who prefer and live in cardependent areas; those who prefer walkable neighborhoods but are mismatched $(21.2 \%$ of our 
sample) are likely not to use active modes of transportation to their full potential. Increasing housing supply in more walkable neighborhoods could encourage a significant part of the population to engage in more active modes of transportation, despite the relatively limited variability in the built environment across the Waterloo Region.

At the same time, $14.6 \%$ of study participants prefer low walkability neighborhoods while living in high walkability neighborhoods. Given that relatively minor changes in environmental variability relate to substantial differences in walking and driving behavior, we suggest that an appropriate policy response to this mismatch could be to prioritise the installation of features that are supportive of active transportation in suburban developments. Such strategies should be designed to minimise objection amongst suburban dwellers with preferences for more cardependent neighborhoods. In order to evaluate the potential level of support for specific differences in neighborhood design, Likert-scale responses were averaged by neighborhood preference quartile for each of the trade-off questions posed to participants (Figure 4). Among participants who strongly prefer a car-dependent environment, the most popular options were providing more space for pedestrian and cycling facilities (trade-off number 6), followed by trading off smaller homes for more active transportation choices (trade-off number 5). All respondents, regardless of their preference quartile, were most reluctant to sacrifice low density living environments to improve neighborhood "liveliness" or "urban vitality" (trade-off number $3)$.

These findings suggest that planners seeking to improve walking behavior while maintaining suburban character in new developments could potentially create favorable environments for a large proportion of the population. Such strategies may include building smaller single-family homes on smaller lots, building narrower roads to increase density, incorporating different housing typologies creatively within a single-family home design, installing bicycle lanes and bicycle parking, and building more off-street pedestrian pathways and trails. Enhancing and adding bicycle and pedestrian pathways would increase the connectivity and density of active-transportation corridors, perhaps helping to decrease the distances households have to travel to access stores and services by active transport modes. Such features may provoke less local opposition and are relatively simple to incorporate into both new and existing developments.

We also showed that obesity and/or lifestyle factors that beget obesity may in fact shape people's neighbourhood preferences. This dynamic could operate in tandem with low walkability contributing to obesity through a lack of calorific burning, as has been surmised by previous studies. Since obesity can render walking more difficult, neighborhoods that prioritise vehiclebased mobility may be more appealing to obese individuals. The planning implications of this finding are important: while the concept of walkable neighborhoods may appeal to (generally younger and more active) populations for whom the 'smart city' tenets of liveability, workability and sustainability are important to achieve (Mayaud et al., 2018), tackling reticence to walking will require different solutions. Reducing preference for low walkability amongst obese populations may focus on strengthening regulation in the food industry (Swinburn, 2008), either at the provincial or national level. Policies that promote healthy diets, which could be relatively easily implemented at Waterloo's regional scale, may help to initially reduce obesity rates and eventually boost demand for walkable neighborhoods. Such policies could be applied together with the more traditional planning interventions described above. 


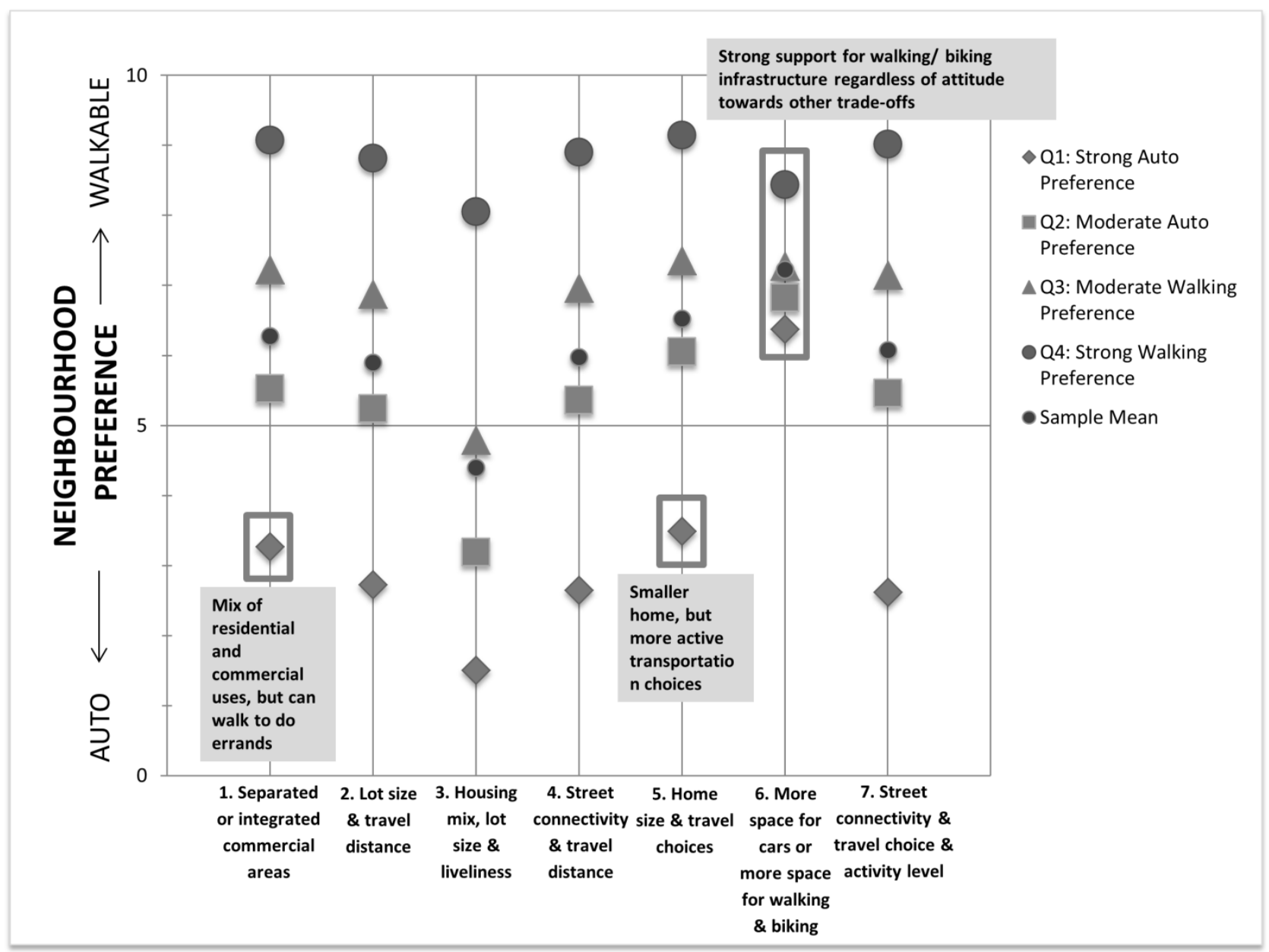

Figure 4. Support for walkable neighborhood trade-offs for respondents by neighborhood preference quartile. Those responses that are discussed in detail in the main text are highlighted by boxes.

While this study seeks to present results and policy recommendations that are robust across midsized city regions, several limitations deserve attention. The lack of environmental variability in Waterloo Region could limit the interpretability of our results, since it limits the points of reference study participants may have had when stating their preferences for walkability. In comparison, variability in residential and commercial densities is much higher in larger cities such as Toronto and Vancouver (Table 1), so preferences expressed in survey-based studies such as this one could be shaped by the context in which respondents actually reside. Whilst the trade-offs used for assessing residential attitudes help to uncover underlying preferences for specific neighborhood design attributes, we acknowledge that the neighborhood design features presented to respondents are not always necessary or clear-cut. There are middle grounds: for instance, careful site-specific design can help to mitigate some of the perceived impacts of high-density development, such as combining different housing typologies in an overarching traditional suburban design. Moreover, our datasets are cross sectional, as opposed to longitudinal. Individual preferences could change over time, but it is not possible to determine from this study if living in a certain neighbourhood type can gradually change the preferences of the residents in that neighbourhood. 


\section{Conclusion}

This paper examined relationships between residential preference, neighborhood walkability, and active transportation in a midsized Canadian city region. Neighborhood preference was assessed through a series of illustrated trade-offs to gauge the level of demand for walkable versus cardependent neighborhood types. Neighborhood walkability was assessed objectively using a detailed GIS-based walkability index that includes sidewalk coverage. Results demonstrate a substantial unmet demand for walkability. Models show that neighborhood preference and the built environment of residential neighborhoods are positively associated with utilitarian and recreational walking. Walkability is also significantly associated with fewer vehicle kilometers traveled. However, only preference for walkability (and not the neighborhood type respondents actually live in) was significantly associated with lower rates of obesity. This finding differs from previous similar studies (e.g., Frank et al. 2015; Kowaleski-Jones et al. 2018), which found that individuals living in the highest walkability quartile were less likely to be obese than individuals living in the lowest quartile. The discrepancy may be attributable to the relatively low variability in walkability in Waterloo Region compared with larger cities and deserves attention when devising future studies in this field.

It is encouraging that relatively minor differences in the built environment are associated with reduced driving and increased walking behavior. This suggests that planning strategies designed to foster active travel and less driving will likely be effective for certain groups in the Waterloo Region. The 2018 opening of the new ION rail system in the Waterloo Region, in conjunction with more aggressive land-use policies promoting walkability at station areas, is an appropriate policy response to meet the unmet demand documented in this study. The existing demand for more walkable neighborhoods could also be met in less urbanized areas of the region by installing features that are supportive of active transportation but still maintain the character of suburban developments. Prioritizing interventions that are simple to implement and least likely to provoke opposition, particularly among individuals preferring more car-dependent neighborhoods, will be key to success in this regard.

\section{References}

Badland, Hannah M, Melody Oliver, Robin A Kearns, Suzanne Mavoa, Karen Witten, Mitch J Duncan, and G David Batty. 2012. Association of neighbourhood residence and preferences with the built environment, work-related travel behaviours, and health implications for employed adults: Findings from the URBAN study. Social Science \& Medicine no. 75 (8):1469-1476.

Berke, Ethan M, et al. 2007. Association of the built environment with physical activity and obesity in older persons. American Journal of Public Health 97(3):486-492.

Booth GL, Creatore MI, Moineddin R, Gozdyra P, Weyman JT, Matheson FI, Glazier RH. 2013. Unwalkable neighborhoods, poverty, and the risk of diabetes among recent immigrants to Canada compared with long-term residents. Diabetes Care no.36(2):302-308. 
Boyle, Austin, Barilleaux, Charlers and Scheller, Daniel. 2014. Does walkability influence housing prices? Social Science Quarterly 95(3): 852-867.

Bunting, Trudi, Pierre Filion, Heidi Hoernig, Mark Seasons, and Jeff Lederer. 2007. Density, size, dispersion: Towards understanding the structural dynamics of mid-size cities. Canadian Journal of Urban Research no. 16 (2):27.

Cao, Xinyu. 2008. Is Alternative Development Undersupplied ? Examination of Residential Preferences and Choices of Northern California Movers. Transportation Research Record no. 2077:97-105.

Cervero, Robert. 1996. Jobs-housing balance revisited: trends and impacts in the San Francisco Bay Area. Journal of the American planning association no. 62 (4):492-511.

Chiu, Maria, Baiju R Shah, Laura C Maclagan, Mohammad-Reza Rezai, Peter C Austin, and Jack V Tu. 2015. Walk Score ${ }^{\circledR}$ and the prevalence of utilitarian walking and obesity among Ontario adults: A cross-sectional study. Health reports no. 26 (7):3.

Creatore, Maria I, Glazier, Richard H, Moineddin Rahim, et al. 2016. Association of neighborhood walkability with change in overweight, obesity, and diabetes. Journal of the American Medical Association 315(20):2211-2220.

De Vos, Jonas, Ben Derudder, Veronique Van Acker, and Frank Witlox. 2012. Reducing car use: changing attitudes or relocating? The influence of residential dissonance on travel behavior. Journal of Transport Geography no. 22:1-9.

Ewing, Reid, and Robert Cervero. 2010. Travel and the built environment: a meta-analysis. Journal of the American planning association no. 76 (3):265-294.

Frank, Lawrence D, Suzanne E Kershaw, James E Chapman, Monica Campbell, Helena M Swinkels. 2015. The unmet demand for walkability: Disparities between preferences and actual choices for residential environments in Toronto and Vancouver. Canadian Journal of Public Health no.106:12-20.

Frank, Lawrence D, James F Sallis, Brian E Saelens, Lauren Leary, Kelli Cain, Terry L Conway, and Paul M Hess. 2010. The development of a walkability index: application to the Neighborhood Quality of Life Study. British Journal of Sports Medicine no. 44 (13):924-933.

Frank, Lawrence Douglas, Brian E. Saelens, Ken E. Powell, and James E. Chapman. 2007. Stepping towards causation: Do built environments or neighborhood and travel preferences explain physical activity, driving, and obesity? Social Science \& Medicine no. 65:1898-1914.

Frank LD, Schmid T, Sallis JF, Chapman J, Saelens B. 2005. Linking objective physical activity data with objective measures of urban form: Findings from SMARTRAQ. American Journal of Preventative Medicine no. 28(2):117-25. 
Giles-Corti, Billie, Anna Timperio, Fiona Bull, and Terri Pikora. 2005. Understanding physical activity environmental correlates: increased specificity for ecological models. Exercise and sport sciences reviews no. 33 (4):175-181.

Howley, Peter. 2009. Land use policy attitudes towards compact city living : Towards a greater understanding of residential behaviour. Journal of Planning Education and Research no. 26:792-798.

Kamruzzaman, Md, Douglas Baker, Simon Washington, and Gavin Turrell. 2013. Residential dissonance and mode choice. Journal of Transport Geography no. 33:12-28.

Kim J, Pagliara F and Preston J. 2005. The intention to move and residential location choice behaviour. Urban Studies no.42(9):1621-36.

Kowaleski-Jones, Lori, Zick, Cathleen, Smith, Ken R, Brown, Barbara, Hanson, Heidi and Fan, Jessie. 2018. Walkable neighborhoods and obesity: Evaluating effects with a propensity score approach. SSM Population Health 6:9-15.

Levine, Jonathan. 1998. Rethinking accessibility and jobs-housing balance. Journal of the American Planning Association no. 64 (2):133-149.

Levine, Jonathan, and Lawrence D. Frank. 2006. Transportation and land-use preferences and residents' neighborhood choices: the sufficiency of compact development in the Atlanta region. Transportation no. 34 (2):255-274.

Handy S, Sallis JF, Weber D, Maibach E and Hollander M. 2008. Is support for traditionally designed communities growing? Evidence from two national surveys. Journal of the American Planning Association no.74(2):209-21.

Levine, Jonathan, Aseem Inam, and Gwo-Wei Torng. 2005. A choice-based rationale for land use and transportation alternatives: Evidence from Boston and Atlanta. Journal of Planning Education and Research no. 24 (3):317-330.

Li F, Harmer P, Cardinal BJ, Vongjaturapat N. Built environment and changes in blood pressure in middle aged and older adults. 2009. Preventative Medicine no.48(3):237-241.

Litman T. 2009. Where We Want To Be: Home Location Preferences and Their Implications for Smart Growth. Victoria Transport Policy Institute. pp.1-40

Maoh, Hanna, and Zhongyuan Tang. 2012. Determinants of normal and extreme commute distance in a sprawled midsize Canadian city: evidence from Windsor, Canada. Journal of Transport Geography no. 25:50-57.

Mayaud, Jerome R, Tran, Martino, Pereira, Rafael HM and Nuttall, Rohan. 2018. Future access to essential services in a growing smart city: The case of Surrey, British Columbia. Computers, Environment and Urban Systems. 
McCormack, Gavin R, Christine Friedenreich, Beverly A Sandalack, Billie Giles-Corti, Patricia K Doyle-Baker, and Alan Shiell. 2012. The relationship between cluster-analysis derived walkability and local recreational and transportation walking among Canadian adults. Health \& place no. 18 (5):1079-1087.

McCormack, Gavin R, and Alan Shiell. 2011. In search of causality: a systematic review of the relationship between the built environment and physical activity among adults. Int J Behav Nutr Phys Act no. 8 (1):125.

Myers D and Gearin E. 2001. Current preferences and future demand for denser residential environments. Housing Policy Debate no.12(4):633-59.

Navaneelan, Tanya, and Teresa Janz. 2014. Adjusting the scales: Obesity in the Canadian population after correcting for respondent bias: Statistics Canada.

Owen N, Cerin E, Leslie E, DuToit L, Coffee N, Frank LD, et al. 2007. Neighborhood walkability and the walking behavior of Australian adults. American Journal of Prventative Medicine, no. 33(5):387-395.

Papas MA, Alberg AJ, Ewing R, Helzlsouer KJ, Gary TL, Klassen AC. 2007. The built environment and obesity. Epidemiological Reviews no.29(27):129-43.

Pender, Terry. 2012. Region could nix bicycle-lane plan in Conestogo. Waterloo Region Record, May 18, 2012.

Pikora, Terri, Billie Giles-Corti, Fiona Bull, Konrad Jamrozik, and Rob Donovan. 2003.

Developing a framework for assessment of the environmental determinants of walking and cycling. Social Science \& Medicine no. 56 (8):1693-1703.

Pivo, Gary, and Jeffrey Fisher. 2010. The walkability premium in commercial real estate investments. Journal of Real Estate Economics 39(2):185-219.

Rauterkus, Stephanie, and Norman Miller. 2011. Residential land value and walkability. Journal of Sustainable Real Estate 3(1):23-43.

Region of Waterloo. 2017. Moving Forward, Phase 1 Report: Trends, Outlooks and Opportunities.

Region of Waterloo Public Health. 2017. Population Projections 2021, 2031 \& 2041, Ontario Ministry of Health and Long-Term Care, IntelliHEALTH Ontario.

Region of Waterloo. 2016. Monitoring change in the Central Transit Corridor.

Rundle, Andrew, et al. (2008). Neighborhood food environment and walkability predict obesity in New York City. Environmental Health Perspectives 117(3):442-447. 
Saelens, Brian E, Sallis James F, Frank Lawrence D. 2003. Environmental correlates of walking and cycling: findings from the transportation, urban design, and planning literatures. Annals of Behavioral Medicine 25:80-91.

Saelens, Brian E, and Susan L Handy. 2008. Built environment correlates of walking: a review. Medicine and Science in Sports and Exercise no. 40 (7 Suppl):S550.

Sallis JF, Saelens BE, Frank LD, Conway TL, Slymen DJ, Cain KL, et al. 2009. Neighborhood built environment and income: Examining multiple health outcomes. Social Science and Medicine no.68(7):1285-93.

Schwanen, Tim, and Patricia Mokhtarian. 2004. The extent and determinants of dissonance between actual and preferred residential neighborhood type. Environment and Planning B: Planning and Design no. 31 (5):759-784.

Schwanen, Tim, and Patricia L. Mokhtarian. 2005. What affects commute mode choice: neighborhood physical structure or preferences toward neighborhoods? Journal of Transport Geography no. 13:83-99.

Statistics Canada. 2017. Waterloo, RM [Census division], Ontario and Ontario Province] (table). Census Profile. 2016 Census. Statistics Canada Catalogue no. 98-316X2016001. Ottawa.

Sultana, Selima, and Joe Weber. 2007. Journey-to-work patterns in the age of sprawl: Evidence from two midsize southern metropolitan areas. The Professional Geographer no. 59 (2):193-208.

Swinburn, Boyd A. 2008. Obesity prevention: The role of policies, laws and regulations. Australia and New Zealand Health Policy 5(12):1-7.

Thompson, Mary, Lawrence D. Frank, Leia Minaker, Josh Van Loon, Kathleen McSpurren, Pat Fisher, and Kim Raine. 2013. Sampling design and data collection for NEWPATH survey. In Transportation Research Board 92nd Annual Meeting. Washington, D.C.

\section{APPENDICES}

\section{Appendix 1: Utilitarian and recreational trips}

\section{Utilitarian trips}

Eating/preparing meals at home or any residence.

Shopping for food (grocery store, convenience store, farmers market)

Dining out (sit-down restaurant or fast food outlet)

Working

School (attending classes) 
Work-related business (sales call, meeting, errand, conference, etc.)

Incidental shopping (gas, housewares, medicine, etc.)

ATM, banking, post office, utilities.

Visiting with friends/relatives.

Medical/dental appointment, treatment

Major shopping (furniture, clothes, auto)

Looking after children

Community meetings, political/civic event, public hearing, voting, etc.

Worship/religious meeting

Waiting for transportation/changing modes of transportation.

Drop-off/pick someone up

\section{Recreational trips}

Watching TV, video games, internet

Going to movies, theatre, sporting event

Dance club, laser tag, paintball etc

Housework (laundry, vacuuming, etc)

Gardening (planting, weeding, etc)

Home repair/maintenance (painting, lawn mowing, carpentry)

Leisurely walking (while shopping, etc)

Brisk walking (for exercise), dog walking

Jogging, running or stationary bike

Aerobic exercise (swimming, jazzercise, step aerobics)

Vigorous sports (tennis, soccer, etc)

Weight lifting

Recreation (vacation, camping, sightseeing) 